\title{
Erratum to: Customization 4.0: \\ Proceedings of the 9th World Mass \\ Customization \& Personalization \\ Conference (MCPC 2017), Aachen, \\ Germany, November 20th-21st, 2017
}

Stephan Hankammer, Kjeld Nielsen, Frank T. Piller,
Günther Schuh, Ning Wang

Erratum to:

S. Hankammer et al. (eds.), Customization 4.0,

Springer Proceedings in Business and Economics, https://doi.org/10.1007/978-3-319-77556-2

In the back cover of the book, the chapter title in the Open Access licence text has now been corrected to be 'An Evaluation Model for Web-based 3D Mass Customization Toolkit Design'

In addition, an incorrect open access license logo was applied at the end of Chapter 23. This has now been corrected to display the correct logo of CC BY.

Also, the copyright holder for Chapter 23 has been corrected to The Author(s).

The updated online version of this book can be found at https://doi.org/10.1007/978-3-319-77556-2 